\title{
Validity and Reliability of Arabic Version of the Patient and Observer Scar Assessment Scale with Burned Patients
}

\author{
ESRAA A.M. ABDELMOTALEB, M.Sc.*; ADEL A. NOSSIER, Ph.D.* and SAMIA M.A. SAIED, M.D.** \\ The Department of Physical Therapy for Surgery, Faculty of Physical Therapy, Cairo University* and \\ The Department of Plastic Surgery, Faculty of Medicine, Sohag University**, Sohag, Egypt
}

\begin{abstract}
Background: Post Burn Scar (PBS) are probably the scars with the highest impact on the quality of life both physical and psychological effects related to excessive scarring may hamper the quality of life. Therefore, there is a need for a simple, reliable and a valid assessment scale to use.

Aim of study: Validity of Arabic language version of patient and observer scar assessment to assess quality of recoveryafter burn injury. Reliability of Arabic language version of patent and observer scare assessment to assess quality of recovery and rate of improvement of scare formation after burn injury.

Subjects and Methods: This study was conducted in three steps, as follows: Step 1: POSAS was translated from English to Arabic (examining both forward and backward translations); Step 2: The test-retest reliability of the scale was investigated; and Step 3: The scale was validated against VSS prospectively on 60 patients who attending outpatient clinic and had their scar assessment by Arabic version of POSAS.

Results: The study group had a mean age of $(36.45 \pm 4.264)$ years ranged from 30 to 45 years, the Arabic version of (POSAS) demonstrated a high degree of internal consistency and stability over time, the cronbach's alpha for observer scale of $($ POSAS $)=0.894$ and for patient scale of $($ POSAS $)=0.9044$, validation of the POSAS (observer scale) against the VSS was strong (with $r$-value $=0.892$ and $p$-value $=0.0001$ ).

Conclusion: The Arabic version of the (POSAS) is an easy-to-administer, simple, reliable and valid tool for assessment of burn scar and for use on Egyptian population. It is advised to be used in clinical practice as well as scientific researches.
\end{abstract}

Key Words: Burn - Scar - Patient and observer scare assessments scale - Validity - Reliability.

\section{Introduction}

DUE to the improvements in burn treatment as provided in highly specialized burn centers, more patients with deep and extended burn injuries do

Correspondence to: Dr. Esraa A.M. Abdelmotaleb, The Departments of Physical Therapy for Surgery, Faculty of Physical Therapy, Cairo University survive nowadays, resulting in a larger group of patients with more extensive scar formation. Scar formation depends on several variables, including the wound treatment, the depth of the burn, the skin type and age of the patient, the healing process [1].

Because of the relatively high prevalence of unfavorable scar formation after burns, most studies on scar assessment and scar treatment are focused on the burn scar, Surgical and dermatologic scars rarely result in extensive scar formation, and since the impact of scar complications strongly correlates with the dimension of the scar (e.g., pain, itching, and fragility), the impact of these types of scars is usually more limited, although also less well studied, Therefore, burn scars are probably the scars with the highest impact on the quality of life both physical and psychological effects related to excessive scarring may hamper the quality of life, including the often lengthy, painful treatment, often resulting in still a suboptimal result, scars may cause pain, itching, and discomfort; and contractures may also constrict mobility. The integration of patients with hypertrophic scars in a society where well-being, individuality, and external appearance have become increasingly important might also be troublesome it has been demonstrated by many authors that burn scars, because of their clearly visible and stigmatizing appearance, may have a major psychological impact, comparable to other chronic (skin) diseases [2] .

A scar assessment scale, which subjectively evaluates the effectiveness of scar therapies, is an important evaluation tool because it describes the impression of experts on the appearance of scars. A scar assessment scale is considered suitable for the comparison of clinical results when it is tested as reliable, feasible, consistent, and valid [3] 
At present, various scar assessment scales are available, but not one has been shown to be reliable, consistent and feasible at the same time. Furthermore, the existing scar assessment scales appear to attach little weight to the opinion of the patient. The newly developed Patient and Observer Scar Assessment Scale consist of two numeric scales: The Patient Scar Assessment Scale (patient scale) and the Observer Scar Assessment Scale (observer scale). The patient and observer scales have to be completed by the patient and observer [4]

\section{Patients and Methods}

Place of study: The study was conducted in the outpatient clinic of Sohag General Hospital.

Type of study: Study was based on a crosssectional design.

Time of study: It was done between October 2016 to March 2017.

One handered burn scars of sixty adult patients attending the outpatient clinic of Sohag General Hospital from both genders, Their ages ranged from 30 to 45 years with major burn $(20 \%)$, Scars on every anatomical location not only specific areas with scar duration above 6 weeks.

The participants write and read Arabic well and Informed consent was obtained from all participants.

All patients were medically stable, followed the instructions during the evaluation and filled the questionnaire farther fully.

Two observers were selected to complete the observer scale both of them were physicians, whom were regularly working with burn patients. They read the instructions on the Patient and Observer Scar Assessment Scale beforehand.

To test the content validity of the new Arabic version of Patient and observer scar assessment scale, ten expert physicians were chosen from Sohag University Hospital with experience not less than 7years, master and phD degrees holders

\section{Statistical analysis:}

All data were analyzed by the statistical program SPSS for Windows 10.5 (SPSS Inc., Chicago, Ill.) version 23, Alpha level set at 0.05 .

The internal consistency ofthe observer and patient scales was assessed by using Cronbach's alpha statistics which considered the values greater than or equal to 0.70 to be acceptable.
The interobserver reliability of the observer scale: Was calculated by the intraclass correlation coefficient (ICC), with its 95 percent confidence interval [5].

The intraobserver reliability of the patient: was calculated by test-retest reliability. The first and second assessments of the patient were used for this purpose for the intraclass correlation coefficient after one- way effect model was selected in SPSS.

The agreement of the measurements of the three observers: Was expressed as the standarderror of measurement (standard error of measurement= mean square residual). The samecalculations were used in the study by Draaijers et al., [6]. The standard error of measurement calculated the amount of error in scores and was expressed in coefficients of variation.

Validity of patient and observer scar assessment scale is evaluated by: The Spearman rho correlation coefficient [5].

\section{Results}

This part of the study is intended to present the collected data through measuring validity of the Arabic version of patient and observer scar assessment by statistical analysis of the content validity using Index of content validity (ICV), Concurrent validity using Pearson's Correlation $(r)$ and predicts validity using the Simple regression model and Beta Standardized Coefficients. Reliability of the Arabic version of patient and observer scar assessment statistically measured by assessment of the internal consistency by Cronbach's alpha, Inter rater reliability and Intra rater reliability by Intraclass Correlation Coefficient (ICC).

Statistical analysis was conducted using SPSS for Windows, version 23 (SPSS, Inc., Chicago, IL). Alpha level set at 0.05 .

The results of this study were presented under the following titles.

Descriptive Analysis of Subjects' General Characteristics:

As shown in Table (1) and Fig. (1), study group consisted of 60 patients 37 males and 23 females [Table (2) and Fig. (2)], there mean age value was (36.45 \pm 4.264$)$ years ranged from 31 to 45 years.

Mean values of age in the study group:

Content validity analysis: According to the experts' opinions the Index of Content Validity (ICV) of all 26 items. All items were relevant 
(Their ICVs ranged from 0.65 to 0.95 ) except items number $1,2,3,10,11,12$ and 17 was irrelevant because it had $\mathrm{ICV}=0.2,0.4,0.6,0.6,0.4,0.6$ and 0.6 respectively and the experts' suggested modification to the translation of those items had been done, the mean CVI of all items was ICV $=0.815$.

Table (2): The correlation analysis between the total score of Arabic version of patient and observer scar assessment (patient section and observer section) in comparison to Vancouver Scar Scale using Pearson Correlation.

Table (3): Simple linear regression using the Overall Opinion of the Observers as the dependent variable and vascularity, pigmentation, pliability, thickness, relief and surface area as independent variables (predictors) revealed that the opinion of the observer was best influenced by four parameters of the observer scale: Vascularity, pliability, pigmentation and surface area in order and not greatly affected by Thickness and Relief as the Standardized Coefficients of Beta.

Table (4): Overall the model is significant with $\mathrm{F}=50.622$ and $p$-value $<0.0001$. Also, $r$ square of the model is 0.851 which mean that the parameters of the observer scale (independent variables) can predict $85.1 \%$ of the Overall Opinion of the Observers (dependent variable) which confirm a good fit of the model.

Table (5): Showed that internal consistency was measured by Cronbach's alpha. Results revealed that the internal consistency of observer scale of the Arabic version of patient and observer scar assessment was good with Cronbach's alpha $=0.894$.

The inter-rater reliability of the Arabic version of patient and observer scar assessment scale was established by testing 60 subjects by two testers. As shown in Table (6) the total value of observer scale mean \pm SD was $(34.72 \pm 12.43)$ for the first tester and (35.28 \pm 13.02$)$ for the second tester. The inter-rater reliability (between two testers) using the Intra-class Correlation Coefficient (ICC).

In Table (7) the total value of observer scale mean \pm SD was $(34.72 \pm 12.43)$ for the first reading of the main tester and (34.3 \pm 12.52$)$ for the second reading for the same tester after 2 weeks also Table (7) showed the total value of patients scale mean \pm SD was $(27.88 \pm 10.33)$ for the first reading of patient and $(26.03 \pm 10.72)$ for the second reading for the same patient after 2 weeks.
Table (1): Patients mean and stander deviation of age.

\begin{tabular}{ll}
\hline & Age (years) \\
\hline Group & Study group \\
Mean & 36.45 \\
S. D. \pm & 4.264 \\
Minimum & 31 \\
Range & 14 \\
Maximum & 45 \\
\hline
\end{tabular}

Table (2): Correlation between the Arabic version of patient and observer scar assessment and Vancouver Scar Scale.

\begin{tabular}{lcc}
\hline \multirow{2}{*}{ Pearson correlation } & \multicolumn{2}{c}{ Before treatment } \\
\cline { 2 - 3 } & $r$ & $p$-value \\
\hline $\begin{array}{l}\text { Total score of observer section } \\
\text { vs Vancouver Scar Scale }\end{array}$ & $0.892^{* * *}$ & 0.0001 \\
$\begin{array}{l}\text { Total score of patient section } \\
\text { vs Vancouver Scar Scale }\end{array}$ & $0.766^{* *}$ & 0.0001 \\
\hline
\end{tabular}

**: Correlation is significant at the 0.01 level.

Table (3): Influence of observer scale parameters on overall opinion of the observers.

\begin{tabular}{|c|c|c|c|c|c|}
\hline & \multicolumn{2}{|c|}{$\begin{array}{c}\text { Unstandardized } \\
\text { Coefficients } \\
\end{array}$} & \multicolumn{2}{|c|}{$\begin{array}{l}\text { Standardized } \\
\text { Coefficients }\end{array}$} & \multirow{2}{*}{$p$-value } \\
\hline & B & $\begin{array}{l}\text { Std. } \\
\text { Error }\end{array}$ & Beta & $t$ & \\
\hline (Constant) & 0.156 & 0.310 & & 0.504 & 0.616 \\
\hline Vascularity & 0.245 & 0.075 & 0.330 & 3.264 & 0.002 \\
\hline Pigmentation & 0.175 & 0.070 & 0.218 & 2.502 & 0.015 \\
\hline Pliability & 0.197 & 0.067 & 0.225 & 2.920 & 0.005 \\
\hline Thickness & 0.090 & 0.064 & 0.106 & 1.422 & 0.161 \\
\hline Relief & 0.069 & 0.063 & 0.071 & 1.097 & 0.277 \\
\hline Surface area & 0.169 & 0.047 & 0.216 & 3.573 & 0.001 \\
\hline
\end{tabular}

Table (4): Simple regression model of observer scale parameters on the overall opinion of the observers.

\begin{tabular}{lllllll}
\hline Model & $\begin{array}{l}\text { Sum of } \\
\text { squares }\end{array}$ & df & $\begin{array}{l}\text { Mean } \\
\text { Square }\end{array}$ & F & value & Square \\
\hline Regression & 186.335 & 6 & 31.056 & 50.622 & 0.000 & 0.851 \\
Residual & 32.515 & 53 & 0.613 & & & \\
\hline Total & 218.850 & 59 & & & & \\
\hline
\end{tabular}


Table (5): Internal consistency of the Arabic version of patient and observer scar assessment by Cronbach's Alpha.

\begin{tabular}{lcc}
\hline & $\begin{array}{c}\text { Cronbach's Alpha } \\
\text { ifItem Deleted }\end{array}$ & $\begin{array}{c}\text { Cronbach's Alpha } \\
\text { of scale as total }\end{array}$ \\
\hline $\begin{array}{l}\text { Observer scale: } \\
\text { Vascularity }\end{array}$ & 0.863 & 0.894 \\
Pigmentation & 0.874 & \\
Pliability & 0.878 & \\
Thickness & 0.879 & \\
Relief & 0.893 & \\
Surface area & 0.903 & \\
Overall Opinion & 0.857 & \\
of the Observers & & \\
Patients scale: & & \\
Question 1 & 0.904 \\
Question 2 & 0.898 & \\
Question 3 & 0.893 & \\
Question 4 & 0.894 \\
Question 5 & 0.890 & \\
Question 6 & 0.879 \\
Overall Opinion & 0.864 \\
of the patient & & \\
\hline
\end{tabular}

Table (6): Intra-class Correlation Coefficient (ICC) for Test re-test Inter rater reliability of Arabic version of observer scale for scar assessment.

\begin{tabular}{lcc}
\hline \multirow{2}{*}{ Observar } & \multicolumn{2}{c}{ Observer scale } \\
\cline { 2 - 3 } & Observar (1) & Observar (2) \\
\hline Mean & 34.72 & 35.28 \\
SD+ & 12.43 & 13.02 \\
ICC & 0.935 & \\
$p$-value & 0.0001 & \\
Significance level & $\mathrm{s}$ \\
\hline
\end{tabular}

Table (7): Intra-class Correlation Coefficient (ICC) for Test re-test Intra rater reliability of Arabic version of patient and observer scale for scar assessment.

\begin{tabular}{llllll}
\hline & \multicolumn{2}{c}{ Observer scale } & & \multicolumn{2}{c}{ Patient scale } \\
\cline { 2 - 3 } \cline { 5 - 6 } & $\begin{array}{c}1^{\text {st }} \\
\text { reading }\end{array}$ & $\begin{array}{c}\text { 2nd } \\
\text { reading }\end{array}$ & & $\begin{array}{c}\text { 1 st } \\
\text { reading }\end{array}$ & $\begin{array}{c}\text { 2nd } \\
\text { reading }\end{array}$ \\
\hline Mean & 34.72 & 34.30 & & 27.88 & 26.03 \\
SD+ & 12.43 & 12.52 & & 10.33 & 10.72 \\
ICC & 0.962 & & 0.927 & \\
$p$-value & 0.0001 & & & 0.0001 & \\
$\begin{array}{c}\text { Significance } \\
\text { level }\end{array}$ & Significant & & Significant & \\
\hline
\end{tabular}

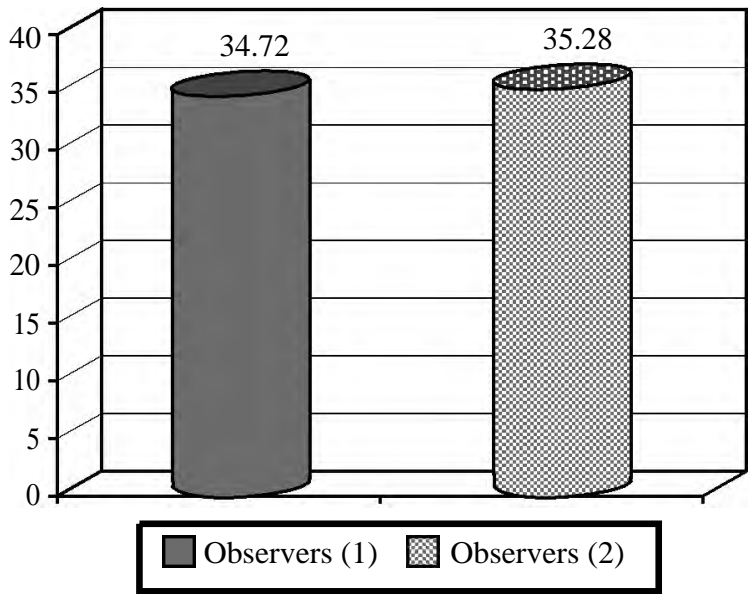

Fig. (1): Mean values Arabic version of observer scale for scar assessment for two observers.

\section{Discussion}

In this study, Arabic adaptation of POSAS was performed following a systematic standardized approach.the study was performed in two main steps first was the translation process from the original English version of the scale into Arabic one according to the publish gidlines and the second was determination of its validity and reliability in the current study the process of Arabic translation had been done according to the international published guidelines with respect to Egyptian accent aiming to be understandable and clear for Egyptian people. As it was made before to dutsh people to be helpful to them because of their language as in POSAS v 2.0 [4].

In the process of content validity in which we asked 10 experts whom were master and MD holders in their opinions on scale items, the items number $1,2,3,10,11,12$ and 17 was irrelevant because it had ICV=0.2, 0.4, 0.6, 0.6, 0.4, 0.6 and 0.6 respectively according to experts opinion, experts who didn't agree these items said that these items need to be changed to be more easy and understandable to the observer who will use this scale and easy for patients who will assessttheirselves. As in item number one (pale) which had the lowest ICV $=0.2$ experts gave a new suggestion for this word to be more clear. all the suggestions were found in suggestions sheet for all items that were not clear. The content validity of the Arabic version of patient and observer scar assessment scale (POSAS) seemed to be good to the average ICV which obtained by experts 'opinions (Mean $\mathrm{ICV}=0.8$ 15)

In the process of reliability, first, the inter-rater reliability (between two observers) using the intra- 
class Correlation Coefficient (ICC) showed that there was a high reliability of Arabic version observer scale (with ICC $=0.935$ and $p$-value $=0.0001$ ).

Secondly, the intra rater reliability the scar assessment measured by Arabic version of patient and observer scar assessment scale at the 1 st and 2 nd occasions by the same tester (intra-rater reliability). Two readings with a week in-between showed that there was a high reliability of Arabic version observer scale (with ICC $=0.962$ and $p$ value $=0.0001$ ).

And in the intra rater reliability for patient scale between the first reading of the patient and the second reading after two weeks. Intra-class Correlation Coefficient (ICC) showed that there was a high reliability of Arabic version of patient scale for scar assessment (with ICC $=0.927$ and $p$-value $=$ 0.0001).

Based on other reliability studies on the original English POSAS, the Arabic version of POSAS showed stronger correlation coefficient as in English one [4].

The internal consistency was measured by Cronbach's alpha. Results revealed that the internal consistency of observer scale of the Arabic version of patient and observer scar assessment was good with Cronbach's alpha $=0.894$ and for the patient scale it was Cronbach's alpha $=0.9044$, indicating acceptale internal consistency while original English one 0.86 for patient and 0.90 for observer scale [4].

In the process of validation of POSAS with Vancouver scare scale (VVS) using Pearson Correlation the analysis showed that there was strong positive correlation between Vancouver Scar Scale and total score of observer section (with $r$-value $=$ 0.892 and $p$-value $=0.0001$ ).

Draaijers et al., [6] found significant correlation between the POSAS scale and the VSS $(\mathrm{p}<0.001)$, as later did Truong et al., [7] $(p<0.001)$.

The correlations between the observer ratings of VSS and the observer component of POSAS were found to be significant (all $p$-values $<0.05$ ). The observer component consistently showed significant correlations with the patients' ratings for the individual categories (all $p$-values <0.05). In VSS, pliability, height, and total score correlated significantly with the patient components of stiffness, thickness, and total scores [8].

In the process of Predictive validity of the scale items in relation to the total score. It was revealed that the opinion of the observer was best influenced by four parameters of the observer scale: Vascularity, Pliability, Pigmentation and Surface Area in order and not greatly affected by Thickness and Relief as found by Van de Kar et al., [4]

\section{Conclusion:}

The findings of the present study showed that:

- The mean CVI (content validity index) of all items was ICV $=0.815$, So the content validity of the Arabic version of patient and observer scar assessment was good according to experts' opinions.

- There was strong positive correlation between Vancouver Scar Scale (VSS) and total score of observer section of (POSAS) (with $r$-value $=$ 0.892 and $p$-value $=0.0001)$.

- The overall opinion of the observer of (POSAS) was best influenced by four parameters of the observer scale: Vascularity, Pliability, Pigmentation and Surface Area and not affected by Thickness and Relief items.

- The internal consistency of observer scale of the Arabic version of patient and observer scar assessment was good with Cronbach's alpha $=0.894$.

- The internal consistency of patients scale of the Arabic version of patient and observer scar assessment was good with Cronbach's alpha $=0.9044$.

- The inter-rater reliability (between two testers) using the Intra-class Correlation Coefficient (ICC) showed that there was a high reliability of Arabic version observer scale (with ICC $=0.935$ and $p$-value $=0.0001$ ).

- The intra-rater reliability using the Intra-class Correlation Coefficient (ICC) showed that there was a high reliability of Arabic version observer scale (with ICC $=0.962$ and $p$-value $=0.0001$ ).

- The expectations that the Arabic version of patient and observer scar assessment scale (POSAS) has a high reliability and validity, easy and good tool to use to assess the burn scar.

\section{References}

1- MONSTREY S., HOEKSEMA H. and VERBELEN J.: "Assessment of burn depth and burn wound healing potential”. Burns, 34: 761, 2008.

2- BROWN B.C., MCKENNA S.P., SIDDHI K., MCGROUTHER D.A. and BAYAT A.: "The hidden cost of skin scars: Quality of life after skin scarring”. J. Plast. Reconstr Aesthet. Surg., $61: 1049$ 
3- NEDELEC B., SHANKOWSKY H.A. and TREDGET E.E.: "Rating the resolving hypertrophic scar: Comparison of the Vancouver Scar Scale and scar volume". J. Burn. Care. Rehabil., 21: 205, 2000.

4- VAN DE KAR A.L., CORION L.U., SMEULDERS M.J., DRAAIJERSLJ, VANDER HORST C.M. and VAN ZUIJLEN P.P.: "Reliable and feasible evaluation of linear scars by the Patient and Observer Scar Assessment Scale". Plast. Reconstr. Surg., 116: 514.

5- STAVROU D., HAIK J., WEISSMANO., GOLDAN O., TESSONE A. and WINKLER E.: "Patient and observer scarassessment scale: How good is it?"Journal of Wound Care., Vol. 18, No 4, 2009.
6- DRAAIJERS L.J., TEMPELMAN F.R., BOTMAN Y.A., TUINEBREIJER W.E., MIDDELKOOP E., KREIS R.W. and VAN ZUIJLEN P.P.: "The patient and observer scar assessment scale: A reliable and feasible tool for scar evaluation”. Plast. Reconstr. Surg., 113: 1960

7- TRUONG P.T., LEE J.C. and SOER B.: "Reliability and validity testing of the Patient and Observer Scar Assessment Scale in evaluating linear scars after breast cancer surgery”. Plast. Reconstr. Surg., 119: 2, 487-494, 2007.

8- CHAE J.K., KIM J.H., KIM E.J. and PARK K.: "Values of a Patient and Observer Scar Assessment Scale to evaluate the facial skin graft scar"Ann. Dermatol., 28 (5): 615-623, 2016.

\title{
صلاحية وفاعلية الأصدار العربى من مقياس تقيييم الندب النداب

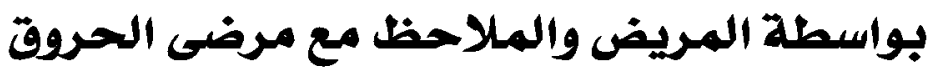

\author{
أجريت هذه الدراسة لتقييم صحة وموثوقية النسخة العربية من مقياس تقييم الندب بواسطة المريض والملاحظ مع مرضى المئ الحروق.

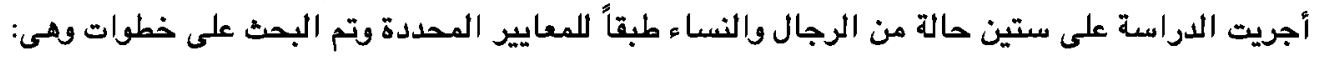 \\ ا- ترجمة تقيم الندب بواسطة المريض والملاحظ من الأنجليزية الى العربية ثم بعد ذلك من العربية مرة أخرى للأنجليزية بعد تقييم

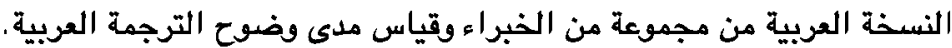 \\ r- تم التحقق من موثوقية الأختبار وإعادة الأختبار للنسخة العربية من مقياس تقييم الندب بواسطة المريض والملاحظظ (مقياس المريض).

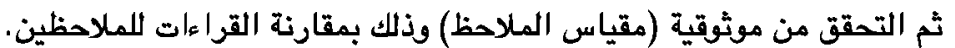

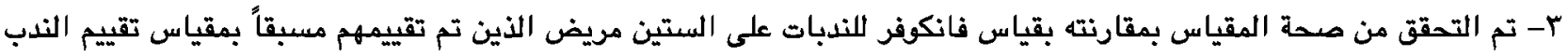

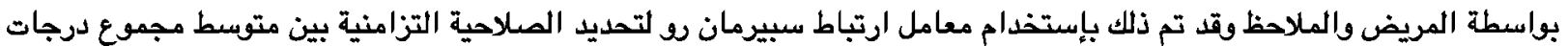

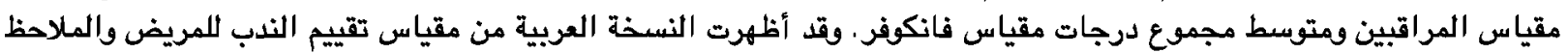 \\ درجة عالية من الألتساق الداخلى والأستقرار مع مرودالوقت، أللفا كرونباخ لمقياس تقييم الندب للمريض والمئ والملاحظ (مقياس المراقب)

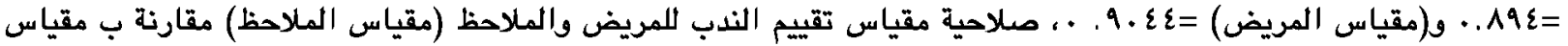

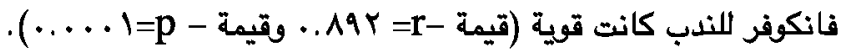 \\ وقد نستنتج أن النسخة العربية من مقياس تقييم الندب للمريض والملاحظ أداة سهلة وبسيطة وموثقق بها وصحيحة لتقييم ندبات

